\title{
Utility of endoscopic pinch biopsy after argon plasma coagulation treatment for diagnosing scirrhous gastric carcinoma
}

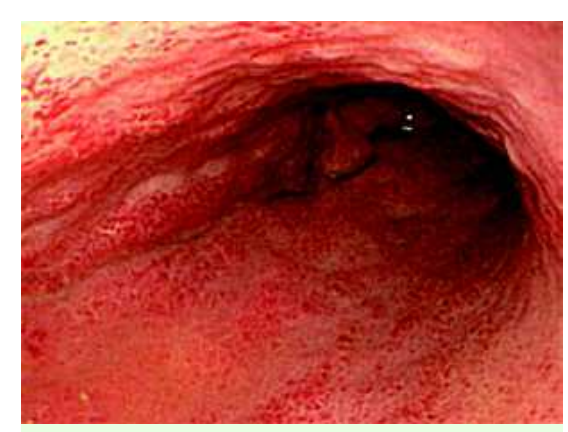

Fig. 1 Endoscopic view of the stomach. The stomach was very rigid and could not be distended with air; it was covered with roughened mucosa that was red and edematous. No erosions or ulcerations were seen.

Scirrhous gastric carcinoma is a diffusely infiltrating type of poorly differentiated gastric carcinoma. It is characterized by cancer cell infiltration and proliferation beneath the gastric mucosa with marked stromal fibrosis [1]. The gastric wall is thickened and stiffened due to diffuse infiltration and proliferation of cancer cells with extensive stromal fibrosis. Endoscopy is useful for assessing the growth pattern, but it is very difficult to obtain an appropriate sample with a routine pinch biopsy. However, after utilizing argon plasma coagulation (APC) to remove the superficial gastric epithelium and cauterize the denuded surface, we were easily able to confirm the diagnosis of scirrhous gastric carcinoma with pinch biopsy.
A 79-year-old woman attended a clinic because of upper abdominal discomfort. Gastrointestinal endoscopy strongly suggested the presence of advanced gastric cancer, but no cancer cells were found in routine biopsy specimens. The patient was referred to our hospital for definitive diagnosis and further treatment. At gastrointestinal endoscopy, the stomach was very hard and could not be distended with air; it was covered with roughened mucosa that was red and edematous, but no erosions or ulcerations were seen ( Fig. 1). Biopsy was done again, but a histopathological diagnosis was not obtained.

To obtain a definitive diagnosis, biopsy after APC treatment was utilized [2]. APC treatment included $50 \mathrm{~W}$ soft-mode coagulation and $0.5 \mathrm{~L} / \mathrm{min}$ argon gas (ICC200; Erbe Co., Tübingen, Germany). The first biopsy after APC treatment yielded a definite histopathological diagnosis; cancer cells were observed beneath the APC-burned area in the biopsied sample ( Fig. 2). The cancer cells, clustered together, were small-sized, atypical cells that contained PAS-positive material in their cytoplasm. On the basis of these findings, a definite histopathological diagnosis of poorly differentiated adenocarcinoma was made.

\section{Endoscopy_UCTN_Code_TTT_1AO_2AC}

\section{T. Kato ${ }^{1}$, M. Fujisaki ${ }^{2}$, H. Tajiri ${ }^{1}$}

Division of Gastroenterology and Hepatology, Department of Internal Medicine, The Jikei University School of Medicine, Tokyo, Japan

Department of Surgery, The Jikei University School of Medicine, Tokyo, Japan

\section{References}

1 Nakazawa K, Yashiro M, Hirakawa K. Keratinocyte growth factor produced by gastric fibroblasts specifically stimulates proliferation of cancer cells from scirrhous gastric carcinoma. Cancer Res 2003; 63: 88488852

2 Farin G, Grund KE. Technology of argon plasma coagulation with particular regard to endoscopic applications. Endosc Surg 1994; $2: 71-77$

\section{Bibliography}

DOI $10.1055 / \mathrm{s}-2007-995553$

Endoscopy 2008; 40: E232

(c) Georg Thieme Verlag KG Stuttgart · New York . ISSN 0013-726X

\section{Corresponding author \\ T. Kato, MD}

Division of Gastroenterology and Hepatology Department of Internal Medicine

The Jikei University School of Medicine Nishi-shinbashi 3-25-8, Minato-ku

Tokyo 1058461

Japan

Fax: +81-3-34594524

tkato@jikei.ac.jp
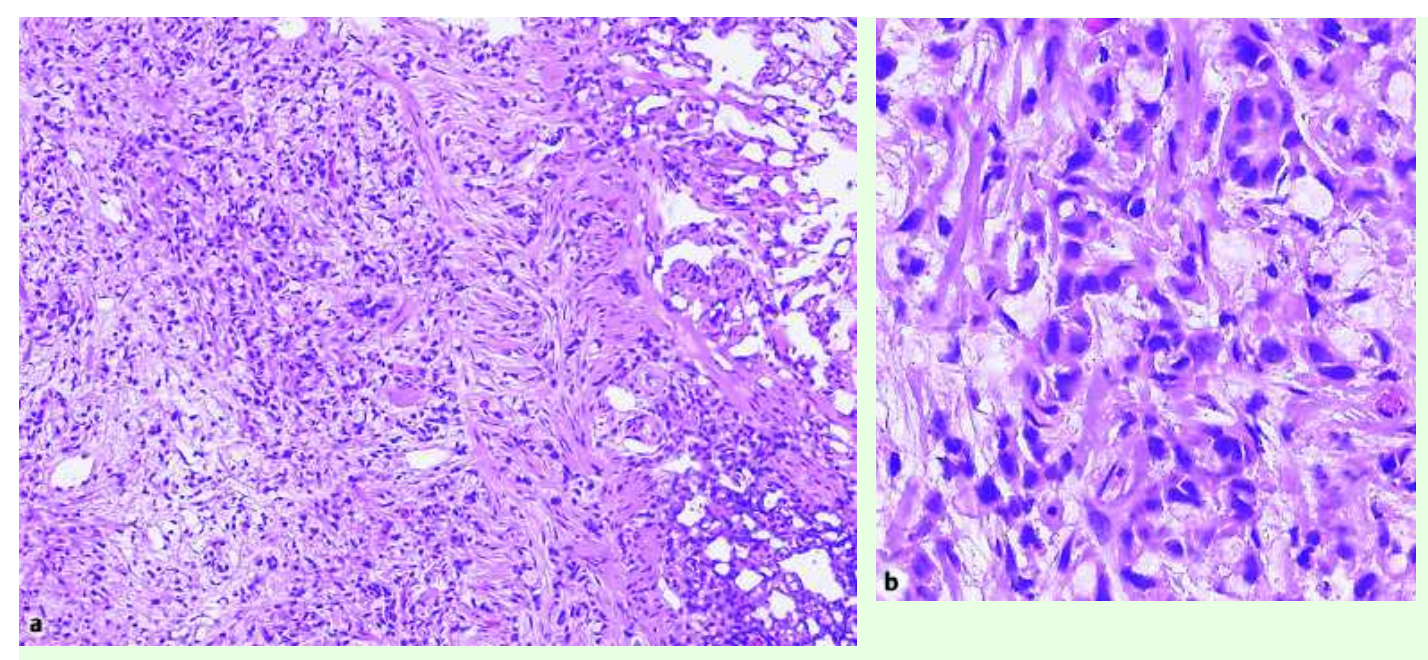

Fig. 2 a Light micrograph of the biopsy specimen at low magnification $(\times 100)$. The margin burned by APC treatment prior to the biopsy is seen on the right half of the figure. The left half of the figure shows the undamaged tissue sample containing cancer cells. b Light micrograph of biopsy specimen at high magnification $(\times 400)$. Poorly differentiated adenocarcinoma cells with signet ring cells are clearly seen. 